\title{
Pore structure characteristics and soil workability along a clay gradient
}

Peter Bilson Obour $^{1 *}$, Thomas Keller,2,3, Mathieu Lamandé1,4, Lars J. Munkholm¹

\author{
${ }^{1}$ Department of Agroecology, Aarhus University, Tjele, Denmark \\ ${ }^{2}$ Department of Natural Resources and Agriculture, Agroscope, Zürich, Switzerland \\ ${ }^{3}$ Department of Soil and Environment, Swedish University of Agricultural Sciences, Uppsala, Sweden \\ ${ }^{4}$ Faculty of Environmental Sciences and Natural Resource Management, Norwegian University of Life Sciences, Ås, Norway
}

\section{Background and aim}

- Clay is a basic soil constituent that governs many soil properties including pore characteristics, which in turn control a range of crucial soil properties and functions.

- Soil workability is an indicator of the ease with which the soil can be tilled to produce the desired soil fragments for crop establishment (Dexter, 1988; Goense, 1987)

- Quantitative information on influence of clay content and matric potential on soil workability very relevant for addressing cultivation problems in agricultural soils with clay variability.

- Our aim was to quantify effect of clay content on soil pore structure characteristics and soil workability for a soil with a naturally occurring clay gradient.

\section{Materials}

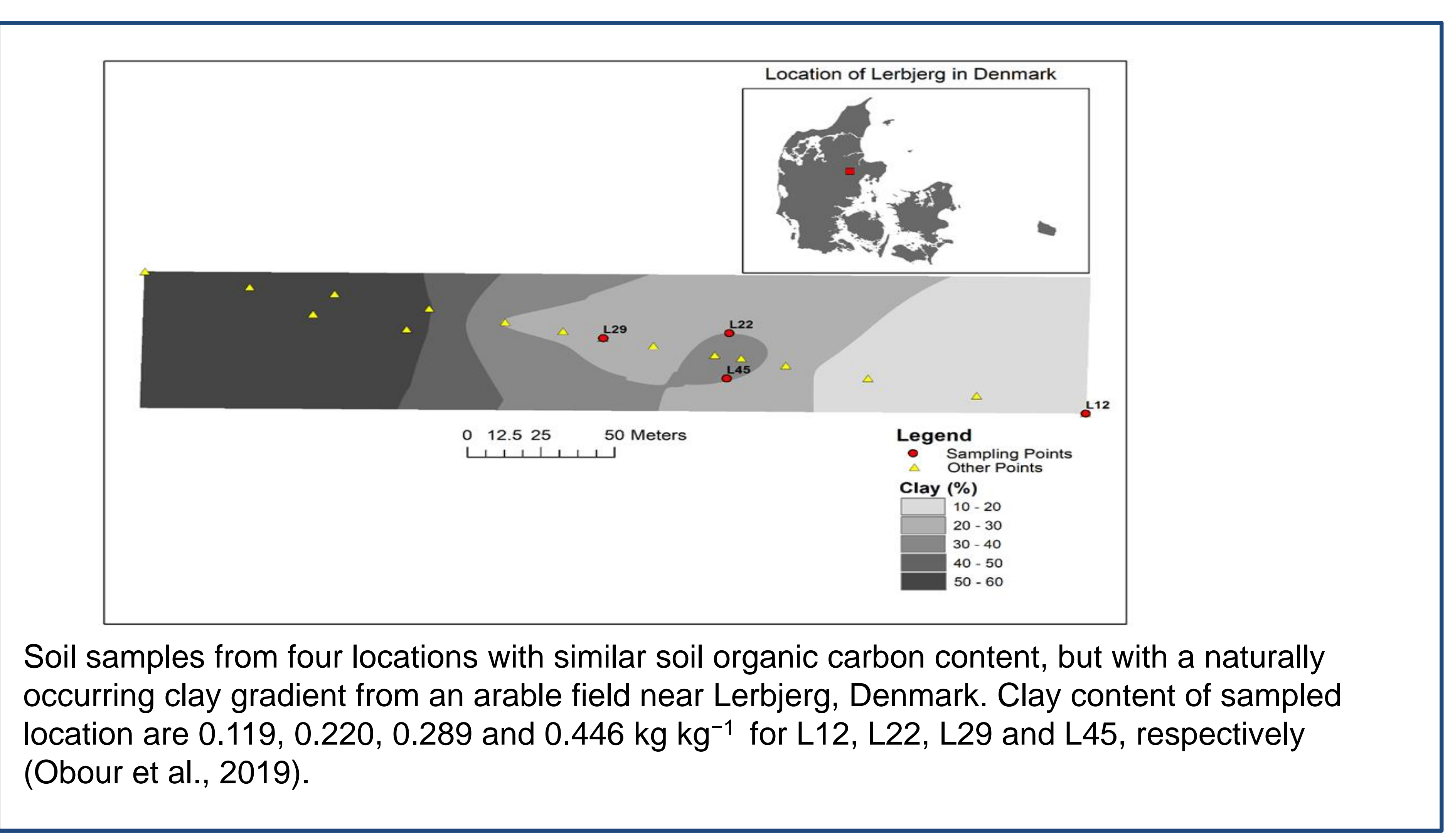

\section{Results}

Bulk density $(\rho b)$; volumetric water content $(\theta)$ at $-100 \mathrm{hPa}$; water content at plastic limit $\left(\theta_{\mathrm{PL}}\right)$; airfilled porosity $\left(\varepsilon_{a}\right)$ at $-100,-300$ and $-1000 \mathrm{hPa}$; relative gas diffusivity $(D p / D o)$, tortuosity $(T)$, air permeability $\left(k_{a}\right)$ and pore organization $\left(P O_{1}=k_{d} / \varepsilon_{a}\right)$ at $-100 \mathrm{hPa}$.

\begin{tabular}{|c|c|c|c|c|}
\hline & \multicolumn{4}{|l|}{ Soil } \\
\hline & L12 & L22 & L29 & L45 \\
\hline$\rho b\left(\mathrm{Mg} \mathrm{m}^{-3}\right)$ & $1.41(0.02)$ & $1.43(0.01)$ & $1.37(0.01)$ & $1.22(0.02)$ \\
\hline$\theta\left(\mathrm{m} \mathrm{m}^{-3}\right),-100 \mathrm{hPa}$ & $0.27(0.00)$ & $0.39(0.01)$ & $0.43(0.00)$ & $0.49(0.01)$ \\
\hline$\theta_{\mathrm{PL}}\left(\mathrm{kg} \mathrm{kg}^{-1}\right)$ & $0.21(0.004)$ & $0.23(0.004)$ & $0.25(0.003)$ & $0.29(0.007)$ \\
\hline$\varepsilon_{a}\left(\mathrm{~m} \mathrm{~m}^{-3}\right),-100 \mathrm{hPa}$ & $0.20(0.01)$ & $0.07(0.01)$ & $0.06(0.01)$ & $0.05(0.00)$ \\
\hline$\varepsilon_{a}\left(\mathrm{~m} \mathrm{~m}^{-3}\right),-300 \mathrm{hPa}$ & $0.25(0.01)$ & $0.11(0.01)$ & $0.10(0.01)$ & $0.09(0.00)$ \\
\hline$\varepsilon_{a}\left(\mathrm{~m} \mathrm{~m}^{-3}\right),-1000 \mathrm{hPa}$ & $0.28(0.01)$ & $0.14(0.01)$ & $0.13(0.01)$ & $0.14(0.01)$ \\
\hline$D p / D o,-100 \mathrm{hPa}$ & $0.021(0.00)$ & $0.006(0.00)$ & $0.004(0.00)$ & $0.002(0.00)$ \\
\hline$k_{a}\left(\mu \mathrm{m}^{2}\right),-100 \mathrm{hPa}$ & $55.4[0.24]$ & $30.5[0.66]$ & $14.5[0.66]$ & $4.3[0.79]$ \\
\hline$P O_{1}\left(\mu \mathrm{m}^{2}\right),-100 \mathrm{hPa}$ & $282.7[0.23]$ & $438.6[0.59]$ & $259.2[0.61]$ & $85.7[0.80]$ \\
\hline$T\left(\mathrm{~m} \mathrm{~m}^{-1}\right),-100 \mathrm{hPa}$ & $5.2(0.33)$ & $9.6(1.70)$ & $14.2(2.40)$ & $21.7(5.15)$ \\
\hline
\end{tabular}

\section{Conclusions ar}

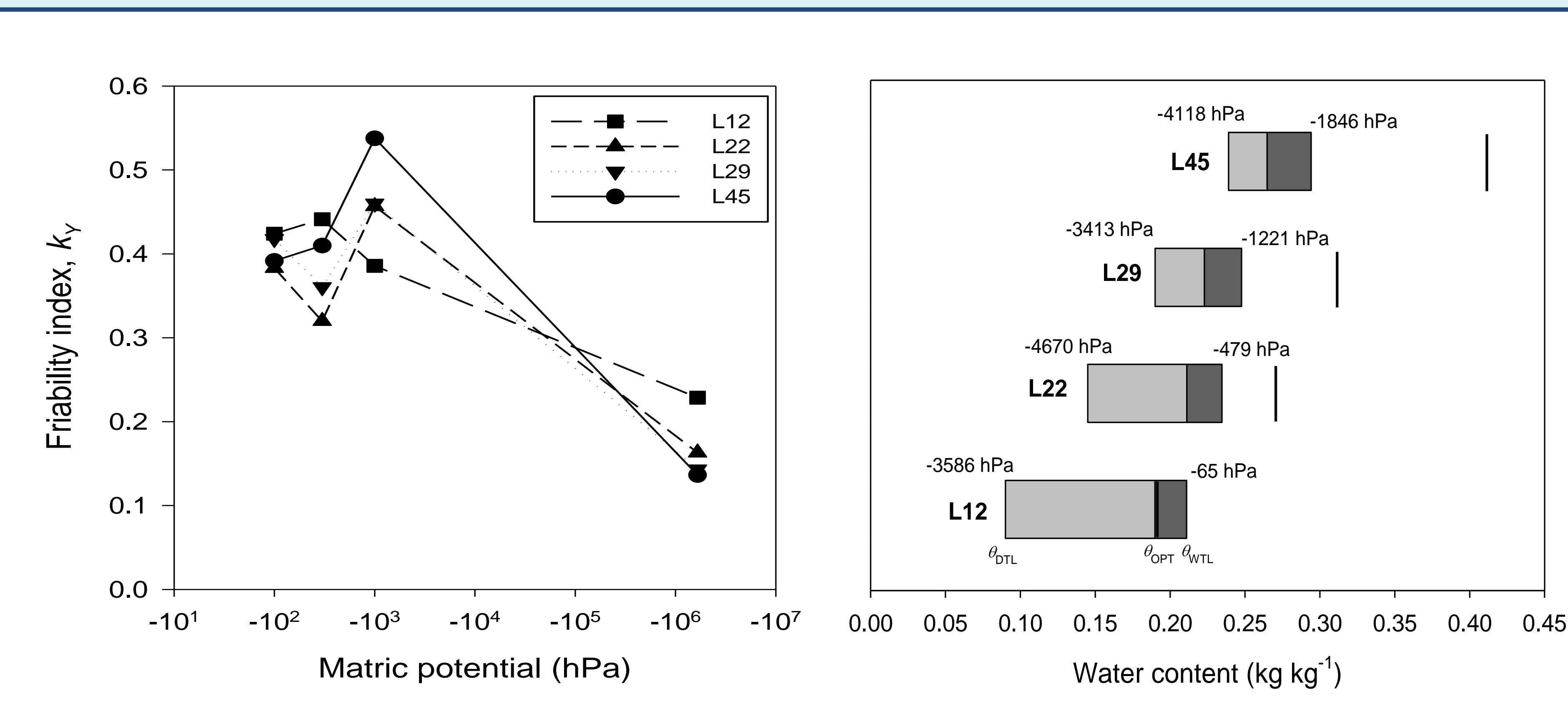

Friability (quantified as the slope of the plot of the natural logarithm of tensile strength for all size fractions and the natural logarithm of the aggregate volume) as a function of matric potential. Friability classification: $<0.1=$ not friable, $0.1-0.2=$ slightly friable, $0.2-0.5=$ friable, $0.5-0.8=$ very friable and $>0.8=$ mechanically unstable (Imhoff et al., 2002).
The range of water contents for tillage for $L 12$, L22, L29 and L45. $\theta_{\mathrm{DTL}}$ : dry tillage limit, $\theta_{\mathrm{OPT}}$ : optimum water content for tillage and $\theta_{\mathrm{WTL}}:$ wet tillage limit estimated using the "consistency approach" (Obour et al., 2018). Solid short vertical lines show water contents at $-100 \mathrm{hPa}$ matric potential. Matric potential ( $\mathrm{hPa}$ ) at $\theta_{\mathrm{WTL}}$ and at $\theta_{\text {DTL }}$ are shown.
Average yearly workability during the spring and autumn over 2014 to 2018 for the investigated soil. Workability limits estimated using the "consistency approach" (Obour et al., 2018). Numbers in parenthesis show the range of workable days.

$\begin{array}{lll}\text { Soil } & \text { Workable days in spring } & \text { Workable days in autumn } \\ \text { L12 } & 35(69) & 37(22) \\ \text { L22 } & 47(66) & 34(23) \\ \text { L29 } & 32(46) & 24(14) \\ \text { L45 } & 0(1) & 0(0)\end{array}$

- The average workable days in the spring and the autumn generally decreased with increasing clay content.

- A uniform tillage operations of a texturally variable field might not be the best management option unless operations are properly scheduled.

- Proper planning and performing tillage operations based on site-specific soil workability is a prerequisite for improving soil fragmentation in tillage and for optimizing resource utilization to reduce the risk of soil structural damage from tillage.

- Overall findings of this study imply that management practices that increase soil macroporosity can potentially decrease aggregate strength and increase the range of water contents for tillage to improve soil workability, which in turn can reduce cultivation problems in agricultural soils with a wide range in clay contents.
Acknowledgements:

We thankful to Stig T. Rasmussen who carried out the sampling and Bodil B.

Christensen, who took care of all the laboratory measurements. A special thanks to the

Graduate School of Science and Technology (GSST), Aarhus University and Oticon

Fonden, Denmark for their financial support during the first author's research stay at

Agroscope Research Institute, Zürich, Switzerland for five months. The study was 